\title{
Direct Interactions of Human Lymphocytes with the Yeast-like Organism, Cryptococcus neoformans
}

Juneann W. Murphy, Michelle R. Hidore, and Si Chai Wong

Department of Microbiology and Immunology, University of Oklahoma Health Sciences Center, Oklahoma City, Oklahoma 73190

\begin{abstract}
Lymphocytes, especially CD4 + T cells, are essential for clearance of the yeast-like organism Cryptococcus neoformans from the infected host. The mechanism(s) by which the lymphocytes facilitate elimination of cryptococci has not been elucidated. It is generally thought, however, that lymphocytes reactive with C. neoformans indirectly function by production of lymphokines to enhance clearance of the organism by natural effector cells such as macrophages. In the present study, we assessed the ability of freshly isolated human lymphocytes to interact directly with $C$. neoformans and to limit the growth of the organism in vitro. We found that large granular lymphocytes (LGL) as well as $T$ cells bound to cryptococcal cells when the lymphocytes were mixed with the cryptococcal cells at a $2: 1$ ratio. The physical binding interactions of the two lymphocyte populations were different. LGL attached to the cryptococcal cells by many microvilli; $T$ lymphocytes associated with the yeast through broad areas of membrane attached to the cryptococcal cell surface. The two types of lymphocyte interactions did not result in phagocytosis but resulted in direct inhibition of cryptococcal growth, making these lymphocyte interactions with cryptococci distinctly different from interactions of monocytes with cryptococci. With the human natural killer (NK) cell line, NK 3.3, we confirmed that NK cells that were present in the LGL population were capable of limiting the growth of $C$. neoformans. Through immunoelectron microscopy, human CD3+ lymphocytes were seen attached to cryptococcal cells and by mass cytolysis, human CD3 + lymphocytes were shown to be responsible for inhibition of $C$. neoformans growth. The direct inhibitory interactions of $\mathrm{NK}$ cells and $\mathrm{T}$ lymphocytes with cryptococcal cells may be important means of host defense against this ubiquitous organism that frequently causes lifethreatening disease in AIDS patients. (J. Clin. Invest. 1993. 91:1553-1566.) Key words: natural killer cells • T cells $\bullet$ large granular lymphocytes • monocytes
\end{abstract}

\section{Introduction}

Cryptococcosis, a disease caused by the ubiquitous yeast-like organism Cryptococcus neoformans, is rapidly climbing to the top of the list of infectious diseases to which AIDS patients

Address correspondence and reprint requests to Dr. Juneann W. Murphy, Department of Microbiology and Immunology, University of Oklahoma Health Sciences Center, PO Box 26901, Oklahoma City, OK 73190.

Received for publication 22 June 1992 and in revised form 23 November 1992.

J. Clin. Invest.

(c) The American Society for Clinical Investigation, Inc.

$0021-9738 / 93 / 04 / 1553 / 14 \$ 2.00$

Volume 91, April 1993, 1553-1566 succumb (1-3). The increased incidence of cryptococcosis in individuals with reduced CD4 + $\mathrm{T}$ lymphocytes along with results from animal studies demonstrate the importance of $\mathrm{T}$ lymphocytes in protection against this fungus $(2,4-8)$. The specific cells and mechanisms by which cryptococci are cleared from the host have not been completely elucidated. Natural killer (NK $)^{1}$ and $T$ cells are two types of lymphocytes that contribute to protection against the eukaryotic microorganism C. neoformans. The ability of NK cells to kill cryptococci in vitro and in vivo has been documented in the murine model (9-16). Results from additional in vitro studies with rat and mouse NK cells provide solid evidence that NK cells interact directly with cryptococcal cells to kill the organism $(14,15,17$, 18). Mouse NK cells inflict damage on these yeast-like targets by attaching to the cryptococcal cells through many microvilli $(14,17)$. The binding interaction results in rearrangement of the cytoplasmic organelles in the NK cell followed by killing of the cryptococcal cell $(11,17)$. NK cells are thought to contribute to clearance of the organism early after infection before the sensitized T lymphocytes have been induced (9, 12, 19-21). Furthermore, evidence from the murine model indicates that, after the anticryptococcal cell-mediated immune response is induced, the sensitized $T$ cells play the major role in directing the protective mechanisms against this opportunistic pathogen $(4,6-8,22,23)$. Although it is possible that the sensitized $\mathrm{T}$ cells function indirectly through other effector cells to eliminate the organisms from the host, it is also possible that the $\mathrm{T}$ lymphocytes interact directly with the cryptococci to mediate killing. Findings from two studies support the latter concept (4, 24). T lymphocytes from $C$. neoformans-immunized mice were shown to inhibit the in vitro growth of cryptococci (24), thus indicating that immune T cells, like NK cells, may directly interact with the cryptococcal cells to eliminate the microorganism. Furthermore, in the mouse model, CD4+ T cells are necessary for the formation of multinucleate giant cells around $C$. neoformans cells at the site of infection, an event that results in containment and eventual elimination of the organism (4).

Since target recognition patterns are different between mouse NK cells and human NK cells (25), there has been some question as to whether human lymphocytes, like mouse lymphocytes, have the ability to bind and directly inhibit cryptococcal growth. For instance, mouse NK cells recognize and kill YAC-1 tumor target cells whereas human NK cells do not effectively kill YAC-1 targets but rather lyse other targets such as K562 tumor cells (25). The effects of human NK cells but not $\mathrm{T}$ lymphocytes on in vitro cryptococcal growth have been previously evaluated by Miller et al. (26). They found that in the presence but not in the absence of anticryptococcal antibody human NK cells killed cryptococcal targets (26). Their

1. Abbreviations used in this paper: CM, complete medium, LGL, large granular lymphocytes; NK, natural killer; NWN nylon wool nonadherent; PE, phycoerythrin. 
work establishes that, with the appropriate signal(s), human NK cells have the capacity to kill cryptococci. In contrast, there is little to no information regarding the direct interaction of freshly isolated human $\mathrm{T}$ cells with $C$. neoformans.

The purpose of the studies presented here was to determine if human NK cells and T lymphocytes would form conjugates with cryptococcal target cells and inhibit target growth in the absence of opsonizing components such as anticryptococcal antibody or complement. Our approach to assessing the anticryptococcal activity of NK cell- and T lymphocyte-enriched fractions was to avoid lymphocyte-enrichment techniques that rely on the use of antibody that could bind to and activate the lymphocytes. Typically, techniques that do not use antibody in the enrichment procedure provide cell populations highly enriched for T lymphocytes; however, they are less effective for purification of NK cells.

Results from our studies with human PBMC fractions show that monocytes, NK cells, and T lymphocytes bind to and inhibit the growth of the fungal target, $C$. neoformans. The variations in each of the three effector cell populations with regard to morphology and the physical characteristics of binding to cryptococcal cells suggest that the anticryptococcal activities observed with the lymphocyte fractions are not due to contaminating monocytes. This impression is confirmed with data from mass cytolysis experiments showing that elimination of monocytes from the lymphocyte fractions does not affect the anticryptococcal activities of the lymphocyte fractions. Further data, obtained after significantly reducing the number of $T$ cells in the NK cell-enriched fractions and after eliminating CD16+ cells (NK cells) from the T cell-enriched fractions by mass cytolysis, indicate there are two distinct peripheral blood lymphocyte populations, NK cells and T cells, that mediate direct anticryptococcal activity in the absence of complement and anticryptococcal antibodies. The ability of human NK cells to inhibit cryptococcal growth in the absence of opsonins was confirmed with the human NK cell clone, NK 3.3. Direct interactions of human $\mathrm{T}$ cells with $C$. neoformans yeast cells was corroborated with immunoelectron micrographs showing that the effector cells bound to cryptococci had CD3 on their surfaces.

\section{Methods}

Monoclonal antibodies. The following purified and fluorochrome-conjugated monoclonal antibodies were purchased from Becton-Dickinson Immunocytometry Systems (Mountain View, CA): anti-CD15 (mouse IgM), anti-CD16 (mouse IgM), phycoerythrin (PE)-conjugated anti-CD16 (mouse IgG ${ }_{1}$ ), FITC-conjugated anti-CD3 (mouse $\mathrm{IgG}_{1}$ ), and mouse irrelevant $\mathrm{IgG}_{1}$-fluorochrome conjugated controls. Mouse IgM for an isotype control, PE-conjugated anti-CD56 (mouse $\mathrm{IgG}_{1}$ ) antibody, and PE-conjugated mouse irrelevant $\mathrm{IgG}_{1}$ for a control were obtained from Coulter Immunology (Hialeah, FL). FITC-conjugated goat $\mathrm{F}\left(\mathrm{ab}^{\prime}\right)_{2}$ anti-mouse IgG + IgM, used as a secondary reagent to recognize anti-CD15, was purchased from Caltag Laboratories, South San Francisco, CA. The anti-CD3 antibody (mouse $\operatorname{IgG}_{2 a}$ ) used for mass cytolysis and immunoelectron microscopy was purified on a G-bind column from supernatants from ATCC CRL 8001 hybridoma (27). The mouse myeloma protein MOPC21, used as an isotype control for the mouse $\mathrm{IgG}_{1}$ antibodies, and UPC10, a mouse $\mathrm{IgG}_{2 \mathrm{a}}$ used as an isotype control for anti-CD3 antibody, were obtained from Organon Teknika-Cappel (Malvern, PA). Goat anti-mouse IgG ( $\mathrm{H}$ and $\mathrm{L}$ ) attached to $1-\mu \mathrm{m}$ carboxylate latex beads used to recognize the mouse monoclonal anti-CD3 antibody and the UPC10 were purchased from Polysciences Inc. (Warrington, PA).
NK 3.3 cells. NK 3.3 is a natural killer cell line cloned from human peripheral blood lymphocytes (28). It exhibits the surface phenotype of CD3-, CD4-, CD5-, CD8-, CD16+, CD38+, CD45+, HLA$\mathrm{DR}+, \mathrm{DP}+, \mathrm{DQ}+$, and Leu7-. NK 3.3 cells have been shown to bind to and lyse traditional NK-sensitive targets (28). The cloned cell line was a generous gift of Dr. Jacki Kornbluth (University of Arkansas, Little Rock, AR). NK 3.3 cells were maintained in our laboratory at 3 $\times 10^{5}$ to $1 \times 10^{6}$ cells $/ \mathrm{ml}$ in RPMI 1640 medium (Gibco Laboratories, Grand Island, NY) supplemented with $15 \%$ heat-inactivated FBS and 15\% Lymphocult-T (Biotest Diagnostics Corp., Fairfield, NJ) (28).

Preparation of human PBMC. Leukocyte buffy coats were obtained from normal volunteers at the Sylvan E. Goldman Blood Institute (Oklahoma City, OK). PBMC were isolated by centrifugation on FicollHypaque (Pharmacia Fine Chemicals, Piscataway, NJ) at $400 \mathrm{~g}$ for 30 $\mathrm{min}$ at room temperature. The PBMC were collected from the inter-

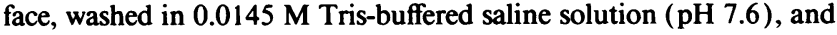
resuspended in complete medium (CM) consisting of RPMI 1640, 100 $\mathrm{U} / \mathrm{ml}$ penicillin, and $100 \mu \mathrm{g} / \mathrm{ml}$ streptomycin supplemented with $5 \%$ heat-inactivated human type $A B$ serum (Gibco Laboratories) $(\mathrm{CM}+\mathrm{HS})$.

Enrichment of PBMC subsets. PBMC suspended in CM + HS were incubated in plastic tissue culture flasks for $1 \mathrm{~h}$ at $37^{\circ} \mathrm{C}$, washed vigorously in similar medium, and the plastic-nonadherent and plastic-adherent cells were collected. The plastic-adherent cells were removed from the plastic with sterile diSPo cell scrapers (American Scientific Products, McGaw Park, IL) and were typically $>92 \%$ monocytes as shown by a modified Wright-Giemsa stain (Diff-Quick Stain; Baxter Scientific, McGaw Park, IL) and by a nonspecific esterase stain. Plastic-nonadherent PBMC were further depleted of adherent monocytes and $\mathrm{B}$ cells by incubation on nylon wool columns for $1 \mathrm{~h}$ at $37^{\circ} \mathrm{C}$. The nylon wool nonadherent (NWN) peripheral blood lymphocytes contained $<2 \%$ monocyte contamination as assessed by flow cytometric analysis for CD15+ cells (29). To enrich for NK cells (low buoyant density lymphocytes) and T cells (high buoyant density lymphocytes), a modification of the discontinuous Percoll density gradient procedure described by Lanier et al. (30) was used. Briefly, NWN lymphocytes were fractionated by centrifugation on three-step discontinuous Percoll (Pharmacia Inc.) gradients consisting of 30, 40, and 50\% Percoll (285 mosmol $/ \mathrm{kg} \mathrm{H}_{2} \mathrm{O}$ ) in PBS supplemented with $10 \%$ FBS. The NK cellenriched population was collected from the interface between the $\mathbf{4 0}$ and $50 \%$ Percoll whereas the T cell-enriched fraction was collected from the bottom of the gradient. Approximately $25 \%$ of the cells recovered were in the low buoyant density fraction and $75 \%$ were in the high buoyant density fraction.

Complement-mediated mass cytolysis of selected cell populations. Complement-mediated lysis was employed as a negative selection procedure for eliminating CD15+ monocytes, CD16+ NK cells, or CD3+ $\mathrm{T}$ cells from selected cell populations. Negative selection procedures were preferred for our purposes rather than positive selection procedures because the latter have the potential to activate the effector cells (25). For depletion of CD15+ cells or CD16+ cells, $5 \times 10^{6}$ effector cells were suspended in $0.5 \mathrm{ml}$ of HBSS (Gibco Laboratories) containing $2 \mu \mathrm{g}$ of anti-CD15+ or anti-CD16+ purified monoclonal antibody, respectively, and incubated for $30 \mathrm{~min}$ at $25^{\circ} \mathrm{C}$. After incubation, the cells were washed with HBSS, resuspended in $1 \mathrm{ml}$ of Low-Tox-H rabbit complement (Accurate Chem. \& Sci. Corp., Westbury, NY), and incubated for $45 \mathrm{~min}$ at $37^{\circ} \mathrm{C}$. After washing the cells with HBSS, CM $+10 \%$ FBS was added to adjust the sample to the original volume. Cell numbers were not adjusted to account for the cells that lysed, however, viability counts were performed to assess the effectiveness of the depletions. For depletion of CD3+ cells, the effector cells were treated as indicated above with $2 \mu \mathrm{g}$ of anti-CD3 antibody and washed in HBSS. The effector cells were then resuspended in $0.5 \mathrm{ml}$ of HBSS containing $2 \mu \mathrm{g}$ of goat (IgG) anti-mouse IgG and incubated for $30 \mathrm{~min}$ at $25^{\circ} \mathrm{C}$. After washing with HBSS, the effector cells were treated with rabbit complement, washed, and resuspended in the initial volume of $\mathrm{CM}$ $+10 \%$ FBS. Viability counts on the cells were made to determine the effectiveness of the mass cytolysis procedure. Isotype-matched mono- 
clonal antibodies or myeloma proteins that did not specifically react with human cells were used as controls to exclude the effects of nonspecific antibody binding.

Immunofluorescent staining for flow cytometry. For indirect immunofluorescent analysis of the CD15 monocyte surface marker, $10^{6}$ effector cells were suspended in PBS supplemented with $0.5 \%$ BSA and normal goat serum (Sigma Chemical Co., St. Louis, MO) $(0.33 \mathrm{mg}$ protein $/ \mathrm{ml}$ ) and incubated for $10 \mathrm{~min}$ at $4^{\circ} \mathrm{C}$. Then mouse anti-human CD15 (IgM) monoclonal antibody ( $1 \mu \mathrm{g}$ ) or a similar concentration of the isotype-matched control antibody was immediately added, and the mixture was incubated for an additional $20 \mathrm{~min}$ at $4^{\circ} \mathrm{C}$. After washing in PBS $+0.5 \%$ BSA, the cells were suspended in similar medium containing $1 \mu \mathrm{g}$ of FITC-conjugated goat $\mathrm{F}\left(\mathrm{ab}^{\prime}\right)_{2}$ anti-mouse $\mathrm{IgG}+\mathrm{IgM}$ and incubated for $20 \mathrm{~min}$ at $4^{\circ} \mathrm{C}$. After three washes in PBS, the cells were fixed in 1\% paraformaldehyde (wt/vol) in PBS and stored at $4^{\circ} \mathrm{C}$ in the dark until analysis $(31)$. For direct immunofluorescent analysis of the CD16, CD56, and CD3 surface markers, $10^{6}$ cells were suspended in PBS $+0.5 \%$ BSA containing $1 \mu \mathrm{g}$ of FITC-conjugated anti-CD3 monoclonal antibody and $1 \mu \mathrm{g}$ of PE-conjugated monoclonal antibody (either anti-CD16 or anti-CD56) and incubated at $4{ }^{\circ} \mathrm{C}$ for $20 \mathrm{~min}$. After three washes with PBS, the cells were fixed and stored as indicated above. Isotype-matched FITC- and PE-conjugated monoclonal antibodies that did not specifically react with human cells were used as controls to exclude nonspecific antibody binding. The immunofluorescent stained cells were analyzed with a FACStar + (BectonDickinson \& Co.) flow cytometer gated to exclude cells that stained with the isotype control antibody.

K562 cytolytic assay. To assess the level of NK cell activity, we performed an 18-h ${ }^{51} \mathrm{Cr}$-release assay with the NK cell-sensitive erythroleukemia cell line, $\mathrm{K} 562$, as targets $(25,32)$. Briefly, ${ }^{51} \mathrm{Cr}$-labeled K562 target cells suspended in CM $+10 \%$ FBS were added to quadruplicate wells of a 96-well round-bottom microtiter plate containing monocytes, low density lymphocytes, or high density lymphocytes in $\mathrm{CM}+10 \% \mathrm{FBS}$ at effector cell to target cell $(\mathrm{E} / \mathrm{T})$ ratios ranging from 50:1 to 12:1. Spontaneous-release samples contained K562 cells in CM $+10 \%$ FBS whereas maximum-release samples contained K562 cells in $2 \mathrm{~N} \mathrm{HCl}$. The volumes in experimental wells, spontaneous release wells, and maximum release wells were adjusted to $0.2 \mathrm{ml}$ with $\mathrm{CM}$ $+10 \%$ FBS. After $18 \mathrm{~h}$ of incubation at $37^{\circ} \mathrm{C}$ in $7 \% \mathrm{CO}_{2}, 0.1 \mathrm{ml}$ of each supernatant was collected from the wells and counted in a gamma counter (Beckman Instruments, Inc., Fullerton, CA). Spontaneous release was typically $<20 \%$ of maximum release. The percentage of ${ }^{51} \mathrm{Cr}$ released from K562 target cells was calculated using the following formula: $\%{ }^{51} \mathrm{Cr}$ released $=[(\mathrm{cpm}$ of experimental supernatant $-\mathrm{cpm}$ of spontaneous supernatant $) / \mathrm{cpm}$ of maximum supernatant $] \times 100$.

Fungal target. C. neoformans, isolate 184A, was maintained on modified Sabouraud's dextrose agar slants. After $1 \mathrm{~d}$ of growth at room temperature, blastoconidia were transferred to $10 \mathrm{ml}$ of $\mathrm{CM}+10 \%$ FBS. The culture was incubated at $37^{\circ} \mathrm{C}$ in $7 \% \mathrm{CO}_{2}$. After $24 \mathrm{~h}$ the cryptococci were washed three times in CM $+10 \%$ FBS and adjusted to the desired cell concentration for each experiment with $\mathrm{CM}+10 \%$ FBS. Cell concentrations were based on hemacytometer counts and confirmed by determining the CFU on modified Sabouraud's dextrose agar plates. The FBS used throughout these studies was heat inactivated and had no detectable anticryptococcal antibodies by the direct whole yeast cell agglutination assay; by an indirect whole yeast cell agglutination assay in which cryptococcal cells were treated with FBS, washed, and reacted with anti-bovine IgG; or by an ELISA using cryptococcal culture filtrate antigen bound to the wells.

C. neoformans growth inhibition assay with monocyte-enriched effector cells. To assess inhibition of $C$. neoformans growth mediated by monocytes, various concentrations of monocyte-enriched effector cells suspended in $0.1 \mathrm{ml}$ of $\mathrm{CM}+10 \% \mathrm{FBS}$ were placed in quadruplicate 12 $\times 75 \mathrm{~mm}$ plastic tubes (Baxter Scientific) containing $1 \times 10^{4}$ cryptococci in $0.1 \mathrm{ml}$ of $\mathrm{CM}+10 \% \mathrm{FCS}$, resulting in effector cell/target cell ratios of 100:1, 50:1, 25:1, and 2:1. Quadruplicate control tubes were prepared that contained cryptococci and medium. After an 18-h incubation at $37^{\circ} \mathrm{C}$ in $7 \% \mathrm{CO}_{2}$, test samples and control samples were washed in $\mathrm{CM}+10 \% \mathrm{FBS}$ and resuspended in $0.2 \mathrm{ml}$ of $0.01 \%$ ( $\mathrm{vol} /$ vol) Triton $\mathrm{X}-100$ in $\mathrm{H}_{2} \mathrm{O}$ to lyse the effector cells, a treatment previously determined to have no effects on the viability of cryptococci (20). The resulting lysates were serially diluted in sterile physiological saline and plated in duplicate on modified Sabouraud's dextrose agar. After $3 \mathrm{~d}$ of incubation at room temperature, CFU were enumerated and the percentage of cryptococcal growth inhibition was determined according to the following formula: \% cryptococcal growth inhibition $=[($ mean control CFU - mean experimental CFU $) /$ mean control CFU] $\times 100$.

C. neoformans growth inhibition assay with lymphocyte-enriched effector cells. To assess inhibition of $C$. neoformans growth by lymphocytes, a modification of the assay previously described by Murphy and McDaniel (13) was used. Preliminary studies were done to determine the effector cell/target cell $(\mathrm{E} / \mathrm{T})$ ratio and the culture conditions that would consistently result in measurable levels of cryptococcal growth inhibition. We found that an E/T ratio of 2:1 consistently gave anticryptococcal activity when human lymphocytes were the effector cells. On the basis of results from our preliminary experiments, the following procedure was used for the experiments presented in this paper. Briefly, $10^{6}$ effector cells (NWN lymphocytes, low density lymphocytes, or high density lymphocytes) and $5 \times 10^{5}$ cryptococcal target cells suspended in CM $+10 \%$ FBS were added to quadruplicate wells of a flat-bottom 96-well microtiter plate (Linbro Scientific Co., Hamden, CT). Quadruplicate control wells contained $5 \times 10^{5}$ cryptococcal target cells in CM $+10 \%$ FBS. Both experimental and control well volumes were adjusted to $0.25 \mathrm{ml}$ with $\mathrm{CM}+10 \% \mathrm{FBS}$. After incubating the plate for $18 \mathrm{~h}$ at $37^{\circ} \mathrm{C}$ in $7 \% \mathrm{CO}_{2}$, the content of each well was serially diluted in sterile physiological saline and plated in duplicate on modified Sabouraud's dextrose agar plates. After $3 \mathrm{~d}$ of incubation at room temperature, CFU were enumerated and the percentage of cryptococcal growth inhibition was determined according to the formula given above.

Assay for effector cell-target cell conjugate formation. Binding of effector cells to $C$. neoformans target cells was assessed according to the procedure previously described $(10,14,17)$. Briefly, effector cells were mixed with cryptococcal target cells at an $\mathrm{E} / \mathrm{T}$ ratio of 2:1 in $\mathrm{CM}$ $+10 \%$ FBS. The effector cells were incubated with cryptococcal cells for $18 \mathrm{~h}$ at $37^{\circ} \mathrm{C}$ in $7 \% \mathrm{CO}_{2}$, conditions initially determined to give maximum human effector cell-cryptococci binding. To facilitate counting of the effector cell-cryptococcal cell conjugates, the samples were stained with $0.25 \%$ alcian blue in serum-free RPMI 1640 medium. Duplicate samples of each conjugate suspension were counted by light microscopy, and the percentage of effector cells bound to target cells was calculated by counting a minimum of 200 effector cells.

Cell preparation for electron microscopy. Monocyte effector cells were mixed with cryptococci at an E/T ratio of 100:1 in $0.2 \mathrm{ml}$ of CM $+10 \%$ FBS. The suspension was placed directly onto Kodacel film (Eastman Kodak Co., Rochester, NY) that was not precoated with poly-L-lysine (Sigma Chemical Co.) and incubated for $18 \mathrm{~h}$ at $37^{\circ} \mathrm{C}$ in $7 \% \mathrm{CO}_{2}$. Lymphocyte effector cells were mixed with $C$. neoformans target cells at an E/T ratio of 2:1 in $0.2 \mathrm{ml}$ of CM + 10\% FBS. After 18 $h$ of incubation at $37^{\circ} \mathrm{C}$ in $7 \% \mathrm{CO}_{2}$, each cell suspension was washed with HBSS, resuspended in $0.2 \mathrm{ml}$ of serum-free RPMI 1640 medium, and placed on Kodacel film that had been precoated with $0.1 \%$ (wt/ vol ) poly-L-lysine in carbonate buffer. The cell suspensions were incubated on the film for $1 \mathrm{~h}$ at $4^{\circ} \mathrm{C}$ to allow the cells to adhere to the film. The samples were then fixed, prepared for scanning electron microscopy or transmission electron microscopy, and viewed as previously described (17).

For immunoelectron microscopy, the T lymphocyte-enriched effector cells were mixed with $C$. neoformans cells and incubated as described above. After the $18 \mathrm{~h}$ incubation, the cell mixtures were washed with ice-cold PBS containing $0.1 \%$ sodium azide $(\mathrm{pH} 7.2)$. The cell pellet was resuspended in $120 \mu \mathrm{l}$ of goat $\mathrm{IgG}(0.16 \mathrm{mg} / \mathrm{ml})$ diluted in PBS with $0.1 \%$ sodium azide and $0.5 \%$ BSA and incubated at room temperature for $20 \mathrm{~min}$. After pelleting the cells and removing the supernatant, the cells were incubated with either $50 \mu \mathrm{l}$ of anti-CD3 
antibody or UPC10 ( $20 \mu \mathrm{g}$ protein $/ \mathrm{ml})$ for $30 \mathrm{~min}$ at room temperature. The cells were washed twice before they were treated for $30 \mathrm{~min}$ with $100 \mu$ l of monodispersed carboxylate latex beads conjugated to goat anti-mouse IgG diluted so that the final suspension contained 100 beads per effector cell. The unbound beads were removed by washing and then the cells were resuspended in cacodylate buffer containing 0.1 $M$ sucrose and $1 \%$ glutaraldehyde before being put onto poly-L-lysinecoated Kodacel film. After adhering the cells to the Kodacel film, the samples were treated as described previously (17).

Statistical analysis. Means and SEM were calculated and Student's $t$ test was used to analyze the data. Groups were considered to be significantly different when the $P$ value was $\leq 0.05$. Where indicated, linearregression analysis and correlation coefficients were determined.

\section{Results}

Characterization of PBMC subsets. Human PBMC were initially separated into plastic adherent and nonadherent cells. The nonadherent cells were further fractionated on nylon wool, and the NWN cells were centrifuged on Percoll density gradients. Before assessing the anticryptococcal activity of the various PBMC fractions, experiments were performed to characterize the predominant cell type(s) present in each fraction. The plastic adherent fractions of the PBMC were examined by flow cytometric analysis and found to contain $>92 \%$ CD15+ cells, a phenotype characteristic of monocytes. Thus, for convenience hereafter the plastic-adherent fractions of PBMC will be referred to as monocytes. The NWN fractions, the low buoyant density lymphocytes (large granular lymphocyte [LGL] or NK cell-enriched fraction ), and the high buoyant density lympho-cytes ( $\mathrm{T}$ cell-enriched fraction) were $(a)$ phenotyped using flow cytometric analyses, $(b)$ evaluated for enrichment of NK cell activity with the K562 cytolytic assay, and (c) assessed for binding and inhibition of $C$. neoformans target cells. Flow cytometric analyses demonstrated that the NWN cells were predominantly CD3 + cells with a small percentage of CD15+ cells and moderate but equivalent percentages of CD56+ and CD16+ cells (Table I). Similar phenotypic analyses after Percoll gradient fractionation of the NWN cells demonstrated enrichment of CD16+ and CD56+ cells, a phenotype typical of NK cells, in the LGL-containing low density lymphocyte fraction whereas the high density fraction contained $>92 \%$ CD3 + cells typical of T lymphocytes ( Table I). NWN cells displayed moderate levels of NK cell activity (Table I) and, as expected, enrichment of CD16+ and CD56+ cells in the LGL fraction correlated with the enrichment of NK cell activity against
K562 target cells. In contrast, enrichment of CD3+ lymphocytes in the $\mathrm{T}$ cell-enriched fraction correlated with a depletion of NK cell activity against K562 target cells (Table I). The levels of $C$. neoformans binding and growth inhibition were comparable when each of these three PBMC fractions were used as the source of effector cells (Table I).

Binding of effector cells to C. neoformans target cells. Since we have previously demonstrated that binding of murine NK cells to cryptococcal target cells is prerequisite to inhibition of cryptococcal growth (17), the various fractions of human PBMC (monocytes, NK cell-enriched low density lymphocytes, and $\mathrm{T}$ cell-enriched high density lymphocytes) were assessed for binding to cryptococcal target cells. Examination of effector cell- $C$. neoformans interactions by scanning and transmission electron microscopy demonstrated that the monocytes as well as cells of the NK and T cell-enriched fractions attached to cryptococcal target cells. However, the physical characteristics of the effector cells and the binding interactions with cryptococci were distinct for each of the three effector cell populations (Fig. 1). Scanning electron micrographs demonstrated that monocytes, as expected, were the largest and most irregular cells present in the three different PBMC fractions (Fig. 1 $A$ ). The monocytes exhibited broadly ruffled or folded membranes that often surrounded either completely or partially the cryptococcal cells (Fig. $1 A$ ). The transmission electron micrographs of the same samples demonstrated phagocytosed cryptococci within the monocytes (Fig. $1 B$ ). In contrast to the monocytes, the lymphocytes were smaller and had a more rounded shape. The membranes of many of the cells in the NK cell-enriched fraction appeared very rough due to their surfaces being covered with numerous thin microvilli. Many of the effector cell- $C$. neoformans conjugates observed within the NK cell-enriched population had effector cells that made contact with the capsular surface of the cryptococcal cell through the tips or edges of several microvilli of the effector cell (Fig. 1 $C)$. Occasionally, in these preparations, conjugates were found in which the effector cells resembled the effector cells in the $\mathrm{T}$ cell-enriched fractions (Fig. 1, $E$ and $F$ ). Stereo-paired scanning electron micrographs (not shown) and transmission electron micrographs of cryptococci bound to effector cells in the NK cell-enriched population (Fig. $1 D$ ) showed that the microvilli of the effector cells penetrated the cryptococcal capsule. In contrast, the majority of the cells in the $T$ cell-enriched fraction displayed wavy folded surfaces. The cell-cell contact sites in the conjugates in the $\mathrm{T}$ cell-enriched population were

Table I. Enrichment of NK Cell Activity in the LGL Fraction of Human PBMC

\begin{tabular}{|c|c|c|c|c|c|c|c|}
\hline \multirow{3}{*}{$\begin{array}{l}\text { PBMC } \\
\text { fraction }\end{array}$} & \multirow{2}{*}{\multicolumn{4}{|c|}{ Phenotype* percent positive }} & \multirow{3}{*}{$\begin{array}{c}\text { Percent }{ }^{51} \mathrm{Cr} \text { release } \\
\text { from } \mathrm{K} 562^{\ddagger} \\
\mathrm{E} / \mathrm{T}=50: 1\end{array}$} & \multicolumn{2}{|c|}{$\begin{array}{c}\text { Percent cryptococcal } \\
\text { E } / \mathrm{T}=2: 1\end{array}$} \\
\hline & & & & & & & Growth \\
\hline & CD3 & CD15 & CD16 & CD56 & & Conjugates & inhibition \\
\hline NWN & $>75$ & $<2$ & $3-10$ & $2-14$ & $29 \pm 8$ & $31 \pm 3^{8}$ & $33 \pm 5$ \\
\hline LGL & $50-75$ & $<1$ & $25-50$ & $25-50$ & $43 \pm 6$ & $25 \pm 2$ & $30 \pm 2$ \\
\hline T Cell & $>92$ & $<1$ & $<5$ & $2-10$ & $10 \pm 1$ & $24 \pm 3$ & $28 \pm 3$ \\
\hline
\end{tabular}

\footnotetext{
* Data are combined from five experiments with a different donor for each experiment; means \pm the standard errors of the means of quadruplicate samples from conjugate and growth inhibition assays.

${ }^{\ddagger}$ Means \pm standard errors of the means of quadruplicate samples from one experiment which is representative of five experiments.

${ }^{\S}$ Represents only two donors.
} 

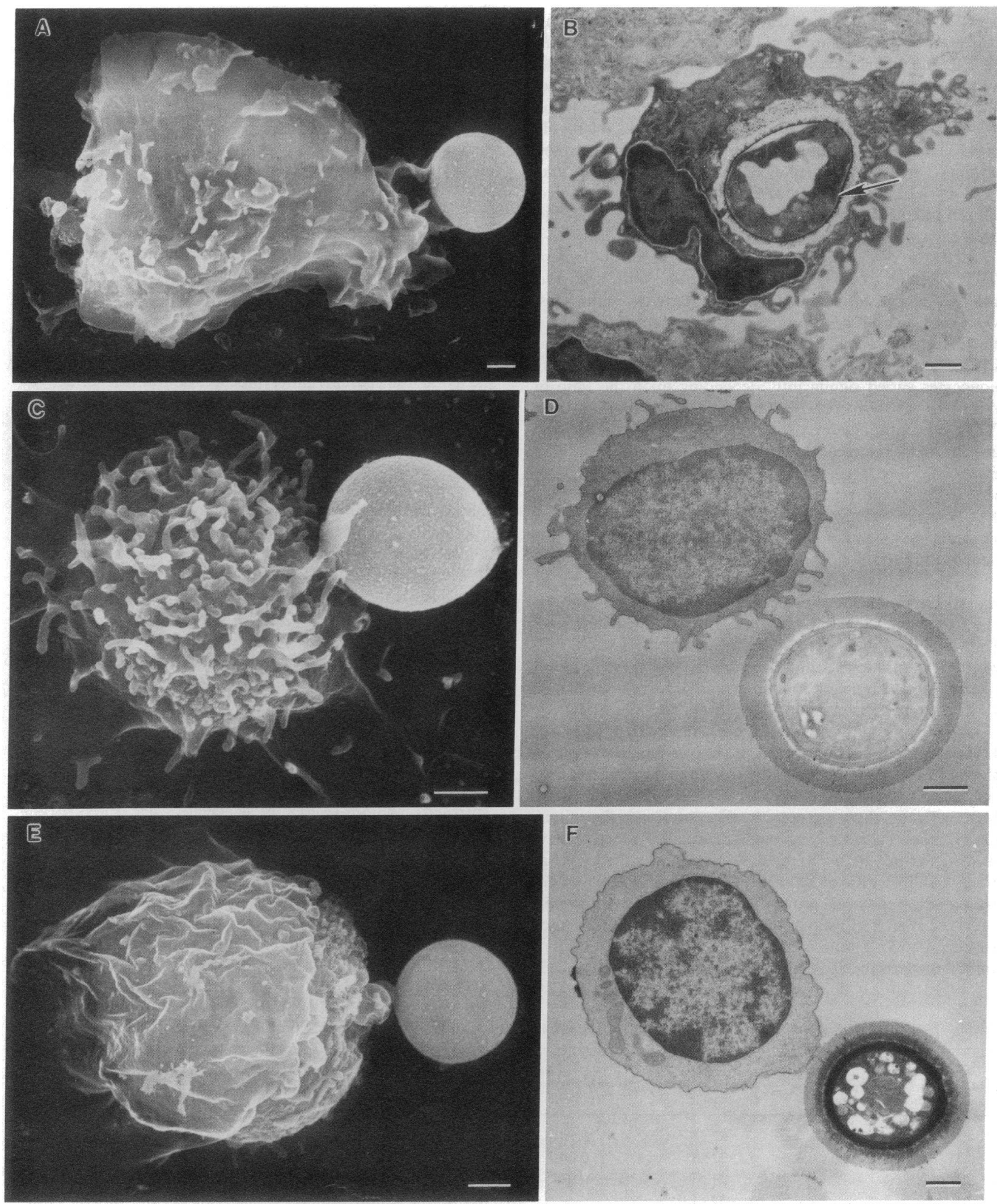

Figure 1. Scanning and transmission electron micrographs of monocyte: $C$. neoformans conjugates ( $A$ and $B$, respectively), LGL: $C$. neoformans conjugates ( $C$ and $D$, respectively), and T cell: $C$. neoformans conjugates ( $E$ and $F$, respectively). Effector cells were incubated with cryptococcal target cells for $18 \mathrm{~h}$ before preparation of the conjugates for electron microscopy. Bars, $1 \mu \mathrm{m}$. 
formed by wide folded protrusions of the lymphocyte membrane extending to the surface of the cryptococcal cell (Fig. $1 E$ and $F$ ). The actual area of contact between the lymphocyte and the cryptococcal cell was much greater than was observed with many of the effector cells of the NK cell-enriched populations that were bound to cryptococci by numerous microvilli (Fig. $1 C$ and $D$ ). Scanning electron microscopy was used for viewing $C$. neoformans-effector cell interactions with NK and $T$ cell-enriched fractions from six different individuals, and cell-cell interactions similar to those shown in Fig. 1 for the respective cell fractions were observed in all cases.

Inhibition of $C$. neoformans growth by fractions of human $P B M C$. To compare human PBMC fractions with regard to anticryptococcal activity and NK cell activity, monocytes, NWN cells, and NK and T cell-enriched fractions were used as effector cells in parallel cryptococcal growth inhibition and K562 cytolytic assays. Anticryptococcal activity mediated by monocytes varied significantly depending upon the ratio of monocytes to cryptococci used in the growth inhibition assay (Table II). Optimal levels of monocyte-mediated cryptococcal growth inhibition occurred with an E/T ratio of 100:1. At a monocyte/cryptococci ratio of $2: 1$, cryptococcal growth was not inhibited, but rather significantly enhanced in relation to the $C$. neoformans control samples $(P=0.004)$ (Table II). The increased cryptococcal growth may have been due to the greater numbers of $C$. neoformans cells per monocyte at this E/T ratio. Possibly the larger numbers of cryptococci destroyed the monocytes, thereby releasing monocyte cytoplasmic components that enhanced the growth of the cryptococci. The viability of the monocytes at the end of the assay in wells with 2:1 E/T ratios was not determined. As expected, monocytes exhibited moderate levels of anti-K562 activity in the 18-h ${ }^{51} \mathrm{Cr}$ release assay at an E/T ratio of 50:1 (Table II).

Anticryptococcal activities at four different $\mathrm{E} / \mathrm{T}$ ratios with LGL and T cell fractions of PBMC from a typical sample are shown in Fig. 2. In several cases, the anticryptococcal activity of LGL fractions was also assessed at a 100:1 E/T ratio. At this high $\mathrm{E} / \mathrm{T}$ ratio, there was considerable variation in detection of anticryptococcal activity among individuals. On occasion, we observed greatly reduced growth inhibition with the LGL fractions at an E/T ratio of 100:1. Because demonstration of LGLmediated cryptococcal growth inhibition was not consistently observed at an E/T ratio of 100:1 but was consistently demonstrated at an $E / T$ ratio of 2:1 and because monocytes did not inhibit the growth of $C$. neoformans at a 2:1 ratio, we used a 2:1

Table II. Monocyte-mediated C. neoformans Growth Inhibition

\begin{tabular}{rccc}
$\begin{array}{c}\text { E/T } \\
\text { ratio* }\end{array}$ & $\begin{array}{c}\text { Percent }{ }^{\text {s1 }} \text { Cr release } \\
\text { from K562 target cells }\end{array}$ & $\begin{array}{c}\text { Percent cryptococcal } \\
\text { growth inhibition }^{*}\end{array}$ & $\begin{array}{c}P \text { value compared } \\
\text { with next lower } \\
\text { E/T ratio }\end{array}$ \\
\hline $100: 1$ & & $57 \pm 4$ & 0.001 \\
$50: 1$ & $31.7 \pm 3.1$ & $32 \pm 3$ & 0.03 \\
$25: 1$ & & $21 \pm 3$ & 0.001 \\
$2: 1$ & & $-52 \pm 13^{\S}$ & \\
\hline
\end{tabular}

* Effector cell/target cell ratio.

${ }^{\ddagger}$ Means and standard errors of the means of quadruplicate samples are presented from one representative experiment of three.

${ }^{8}$ At a 2:1 E/T ratio cryptococcal growth was enhanced over the $C$. neoformans control.

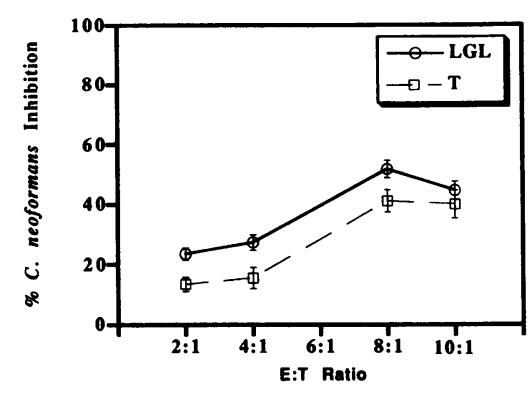

Figure 2. Percent $C$. neoformans growth inhibition at various $\mathrm{E} / \mathrm{T}$ ratios with freshly isolated human LGL- or T cell-enriched fractions as effector cells. Effector cells were incubated with $C$. neoformans cells $\left(10^{5}\right.$ per well ) for $18 \mathrm{~h}$ before determining the percent growth inhibi-

tion. Mean cryptococcal CFU in wells containing only $C$. neoformans cells was $2.7 \times 10^{6} / \mathrm{ml}$ at the end of $18 \mathrm{~h}$.

E/T ratio with lymphocyte populations as effector cells throughout the remainder of the study.

After rigorous monocyte depletion by adherence to plastic and nylon wool, parallel anticryptococcal and anti-K 562 activities of lymphocytes from 10 different donors were assessed at an E/T ratio of 2:1 (Fig. 3). In some cases, data from cells of the same donor are included in Table I and Fig. 3, however, because sufficient numbers of cells to perform all of the assays were not obtained from each donor, results from some individuals are included in Table I that are not represented in Fig. 3 and vice versa. Wide ranges of both cryptococcal growth inhibition and K562 cytolysis were observed depending on the donor (4-33\% cryptococcal growth inhibition and $15-66 \%{ }^{51} \mathrm{Cr}$ release from K562) when NWN cells were used as the effector cells (Fig. 3, a). However, linear-regression analysis demonstrated a positive correlation between the level of cryptococcal growth inhibition and the level of K562 cytolytic activity of NWN cells $(r=0.68)$, suggesting that the NK cells that mediate K562 cytolysis might be responsible for the inhibition of cryptococcal growth. Similar correlation analyses were done with NK cell activity data and cryptococcal growth inhibition data obtained with the NK cell-enriched, LGL fractions (Fig. $3, b$ ) as effector cells and with the NK cell-depleted ( T cellenriched) fractions (Fig. 3,c) as effector cells. The NK cellenriched LGL fractions exhibited a range of 8-52\% K562 cytolytic activity whereas the cryptococcal growth inhibitory activity ranged from 4 to $56 \%$ with a positive correlation between the two parameters of $r=0.9$ (Fig. 3, b). In contrast, the T cell-enriched fractions displayed significantly lower levels of K562 cytolytic activity $(1-23 \% ; P<0.001)$ as would be expected with depletion of NK (CD56+ and CD16+) cells. However, the $\mathrm{T}$ cell-enriched fractions had levels of anticryptococcal activity similar to that of the NK cell-enriched populations $(2-47 \%)$ (Fig. 3, c). When the T cell-enriched fractions were used as the source of effector cells, the correlation between $\mathrm{K} 562$ cytolytic activity and cryptococcal growth inhibition was lower than when NK cell-enriched fractions were the effector cells $(r=0.48$ vs. $r=0.9)$. These data suggest that both the NK and the $\mathrm{T}$ cell-enriched populations contained effector cell(s) capable of limiting cryptococcal growth.

Identity of the effector cells that inhibit $C$. neoformans growth. The anticryptococcal activities of the various PBMC populations were assessed after mass cytolysis procedures designed to produce highly purified populations of monocytes, NK cells, or T cells. To ascertain the effectiveness of mass cytolysis and confirm that monocytes inhibited cryptococcal growth, monocyte-enriched fractions of human PBMC were treated with anti-CD15 or anti-CD16 antibody and C before 

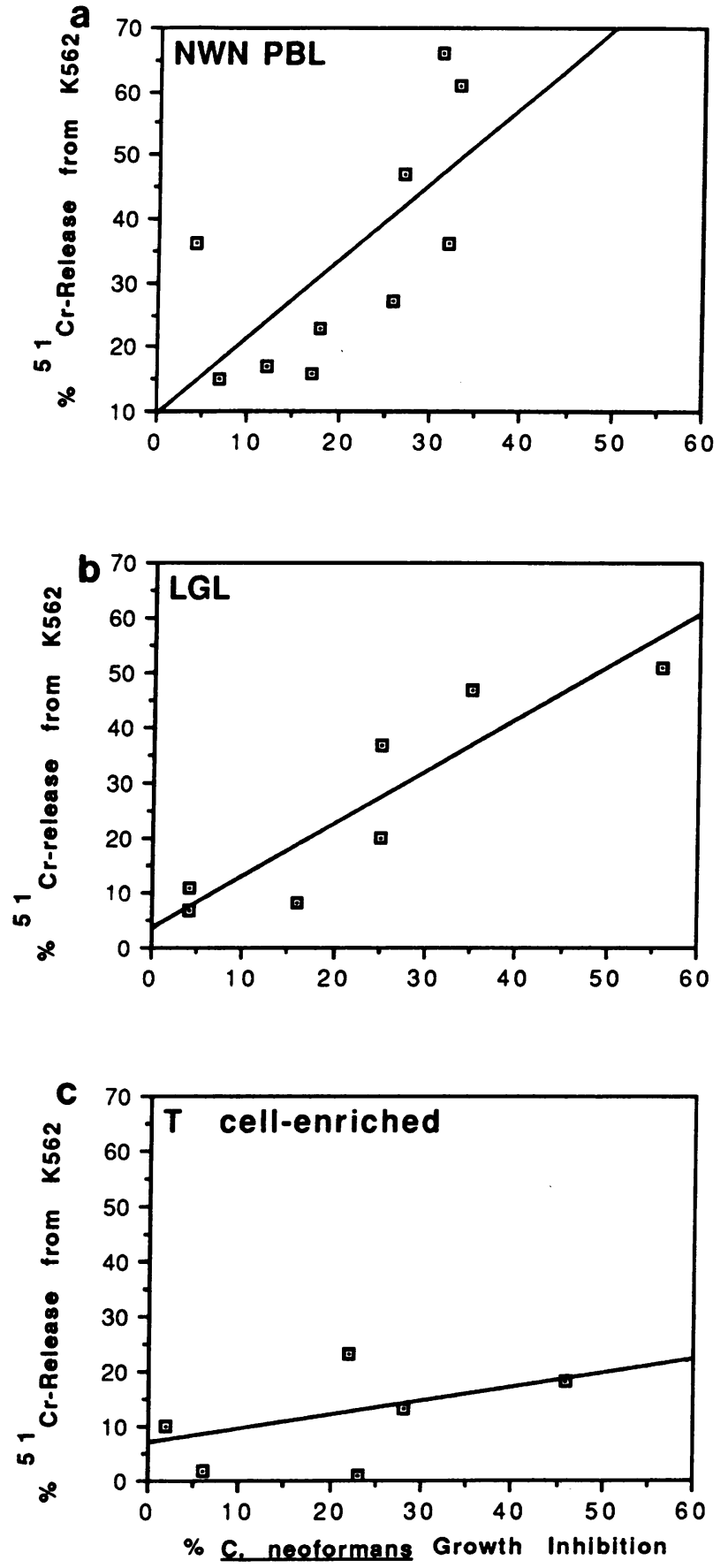

Figure 3. Correlation between lymphocyte-mediated ${ }^{51} \mathrm{Cr}$ release from K562 target cells and $C$. neoformans growth inhibition. NWN PBMC $(a)$, NK cell-enriched LGL $(b)$, and T cells $(c)$ from at least six different donors were used as effector cells in parallel ${ }^{51} \mathrm{Cr}$ release and cryptococcal growth inhibition assays. Each open symbol represents the mean of quadruplicate samples from an individual donor. Solid lines represent the linear regression between the two parameters ( $a$, $r=0.68 ; b, r=0.9 ; c, r=0.48)$.

measuring their anticryptococcal activity using an $\mathrm{E} / \mathrm{T}$ ratio of 100:1 in an 18-h assay. Anti-CD15 (IgM) antibody and C treatment reduced the anticryptococcal activity of the monocyte fraction when compared with the control groups that were treated with $\mathrm{C}$ alone or anti-CD16+ (IgM) antibody and C (Fig. 4).

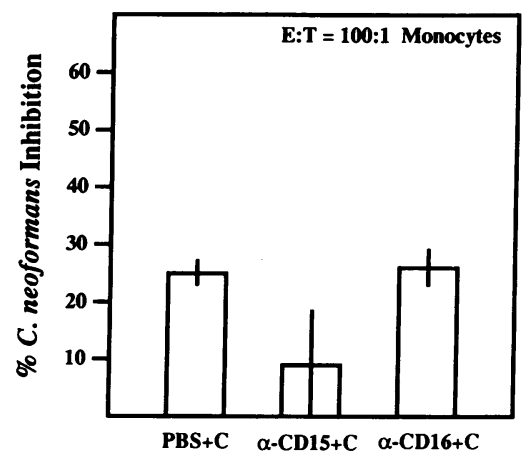

Figure 4. Anticryptococcal activity of human monocytes after treatment with antiCD15 or anti-CD16 and complement $(C)$. Plastic-adherent PBMC were incubated with anti-CD15 or antiCD16 and $\mathrm{C}$ before being mixed with cryptococci at an effector cell/ target cell ratio of $100: 1$ for $18 \mathrm{~h}$ at $37^{\circ} \mathrm{C}$ in $7 \%$

$\mathrm{CO}_{2}$. The mean cryptococcal CFU in wells containing only $C$. neoformans cells was $4.6 \times 10^{5} / \mathrm{ml}$. Treatment with an isotype-matched control antibody (mouse IgM) or phosphate-buffered saline (PBS) and $C$ served as controls. Bars represent the mean \pm the standard error of the mean of quadruplicate samples. Data are representative of four experiments using cells obtained from four different donors.

To confirm that the anti-K562 activities and the anticryptococcal activities displayed by the LGL (NK cell-enriched) fractions and the $T$ cell-enriched fractions were not due to contaminating monocytes, each effector cell fraction was treated with $C$ alone, anti-CD15 and C, or anti-CD16 and C before determining the levels of activity against K562 or cryptococcal targets. Removal of the CD15+ monocytes from the LGL or the T cell-enriched fraction did not reduce the antiK562 activity nor the anticryptococcal activity of either the LGL or the T cell-enriched fraction when compared with the respective activities of the PBS + C-treated controls (Fig. 5). In contrast, anti-CD16 and C treatment of the LGL (NK cellenriched) fraction significantly reduced both the anti-K562 activity $(P<0.001)$ and the anticryptococcal activity $(P=0.001)$ in comparison to the respective activities of the control cell fractions (Fig. 5). Anti-CD16 and C treatment of the T cellenriched fraction significantly diminished the anti-K562 activity $(P=0.001)$ of that fraction, however, the same treatment did not reduce the anticryptococcal activity of the $T$ cellenriched fraction (Fig. 5).

Since the anti-CD16 and $\mathrm{C}$ treatment significantly reduced but did not completely abrogate the NK cell activity ( $P$ $<0.001)$ nor the anticryptococcal activity $(P=0.001)$ of the LGL (NK cell-enriched) fraction and did not reduce the anticryptococcal activity of the $\mathrm{T}$ cell-enriched fraction, conclusions were difficult to make, so we extended the mass cytolysis studies. The next series of PBMC samples were separated as before into LGL and T cell-enriched fractions before treating the cells with mouse IgM as an isotype control for the antiCD16 or with anti-CD16 followed by C treatment. Samples from each cell fraction were retained as untreated controls. The various treated fractions were then $(a)$ analyzed by flow cytometry to determine the number of CD16+ and CD3+ cells in the samples, $(b)$ assessed for their ability to lyse K562 cells, and ( $c$ ) evaluated for their anticryptococcal activity.

The flow cytometric data demonstrated that the LGL fraction was enriched for CD16+ cells as compared with the $\mathrm{T}$ cell fraction (Fig. $6, A$ vs. $D$, untreated groups). The data also confirmed that there was considerable contamination of the LGL fraction with $\mathrm{CD} 3+$ cells (Fig. $6 \mathrm{~A}$, untreated group). In contrast, the $\mathrm{T}$ cell-enriched fraction contained a very minimal number of CD16+ cells (Fig. $6 \mathrm{D}$, untreated group). The flow 


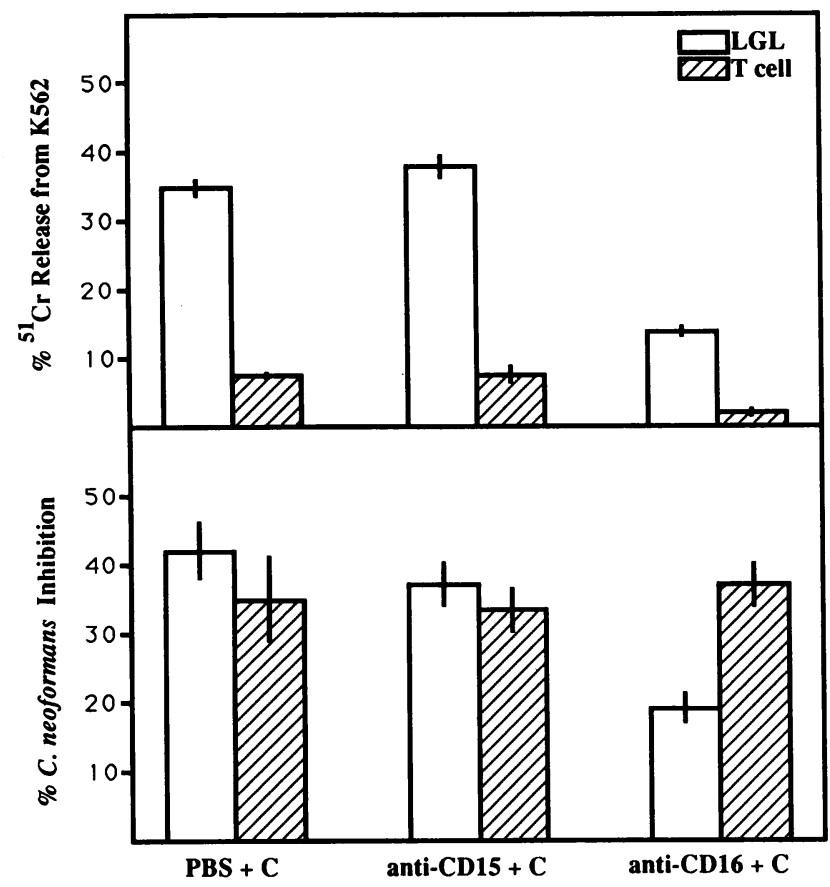

Figure 5. Anticryptococcal activities of human NK cell-enriched and $T$ cell fractions after treatment with phosphate buffered saline (PBS), anti-CD15, or anti-CD16 and complement (C). For depletion of CD15+ cells or CD16+ cells, LGL and T cell fractions obtained after Percoll gradient fractionation of human NWN PBMC were treated with anti-CD15 or anti-CD16, respectively, and C before incubating the effector cells with $\mathrm{K} 562$ target cells at an effector cell to target cell (E/T) ratio of 50:1 or with $C$. neoformans targets at an E/T ratio of $2: 1$ for $18 \mathrm{~h}$ at $37^{\circ} \mathrm{C}$ in $7 \% \mathrm{CO}_{2}$. The mean cryptococcal CFU in wells containing only $C$. neoformans cells was $4.3 \times 10^{6} / \mathrm{ml}$. Bars represent the mean \pm the standard error of the mean of quadruplicate samples. Data are representative of four experiments using cells obtained from four different donors.

cytometric data also showed that the anti-CD16 antibody and C treatment depleted CD16+ cells from both the LGL and the $\mathrm{T}$ cell-enriched fractions without significantly altering the number of CD3+ cells in either cell fraction (Fig. $6 A$ for LGL and $D$ for T cells).

The anti-CD16 and C treatment of the LGL fractions (Fig. $6 \mathrm{~B}$ ) and the T cell-enriched fraction (Fig. $6 \mathrm{E}$ ) significantly reduced the NK cell activity as measured by the lysis of K562 cells of the LGL fraction but not the T cell fraction (LGL, $P$ $<0.023$; T cell, $P=0.33$ ). Although the anticryptococcal activity of the LGL fractions after treatment with anti-CD16 + C was always slightly lower than the anticryptococcal activity of the IgM + C-treated control population, the difference was never significant (Fig. $6 \mathrm{C}$ ). Furthermore, anti-CD16 and $\mathrm{C}$ treatment of the $T$ cell-enriched fraction did not significantly affect the anticryptococcal activity (Fig. $6 F$ ). Because the antiCD16 and C treatment reduced the NK cell activity but did not significantly affect the anticryptococcal activity, it appeared that the CD3 + T cells were inhibiting the cryptococcal growth. Our electron microscopic observations of cells in the $T$ cellenriched fraction binding to $C$. neoformans and our findings that the binding characteristics differed from those of other cell populations (Fig. 1) are in agreement with this suggestion that human $T$ cells might directly affect cryptococci.

To further address the possibility that human $T$ cells di- rectly inhibit cryptococcal growth, a study similar to the previous one was done, but the cell fractions were treated with anti-CD3 antibody and $\mathrm{C}$ or an appropriate isotype-matched control antibody (UPC 10) and C rather than anti-CD16 before determining the anticryptococcal activities of the cell fractions. The efficacy of the depletion was monitored by flow cytometry. The anti-CD3 and $\mathrm{C}$ treatment greatly reduced as compared with the UPC10 + C controls the number of CD3+ cells in the LGL and the T cell-enriched fractions without affecting the numbers of CD16+ cells (Fig. 7, $A$ and $D$, respectively ). Moreover, the anti-CD3 and $C$ treatment did not affect the NK cell activity of either cell fraction (Fig. 7, $B$ and $E$ ). The treatment with anti-CD3 and $\mathrm{C}$, when compared with treatment with UPC 10 and $C$, had no effect on the anticryptococcal activity of the LGL fraction (Fig. $7 C$ ) but did significantly diminish the anticryptococcal activity of the $\mathrm{T}$ cell-enriched fraction $(P<0.002$; Fig. $7 F)$.

Effect of the human NK cell clone NK 3.3 on C. neoformans growth. The reduction of T cells in the LGL population by anti-CD3 antibody and $C$ treatment did not result in a concomitant reduction in anticryptococcal activity (Fig. $7 \mathrm{C}$ ). This result suggested that the NK cells in the population were responsible for the remaining cryptococcal growth inhibitory activity. Since there was a small number of $\mathrm{CD} 3+\mathrm{T}$ cells in the antiCD3 and C-treated LGL population, we could not be certain the anticryptococcal activity was imparted by NK cells. To determine if human NK cells in the absence of opsonins and $\mathrm{T}$ cells could inhibit the growth of $C$. neoformans, we assessed the ability of the human NK cell clone NK 3.3 to inhibit the growth of $C$. neoformans. Data presented in Fig. 8 show that as the NK 3.3 cell/cryptococcal cell ratios were increased from $1: 1$ to $8: 1$, the inhibition of $C$. neoformans growth increased from 0 to $73 \%$ (Fig. $8 \mathrm{~A}$ ). With similar $\mathrm{E} / \mathrm{T}$ ratios, the percent ${ }^{51} \mathrm{Cr}$ release from $\mathrm{K} 562$ tumor targets ranged from 10 to $60 \%$ (Fig. $8 \mathrm{~B}$ ), demonstrating the level of NK cell activity of this clone.

Immunoelectron microscopy. To confirm that T lymphocytes were the effector cells attached to $C$. neoformans, immunolabeling with mouse $\operatorname{IgG}_{2 \mathrm{a}}$ monoclonal anti-CD3 antibody or an irrelevant $\operatorname{IgG}_{2 \mathrm{a}}$, UPC10, followed by anti-mouse IgG bound to latex beads was performed. When conjugates in the $T$ lymphocyte- $C$. neoformans mixtures were immunolabeled with anti-CD3 and the secondary antibody and viewed on the scanning electron microscope, we found that the effector cells attached to cryptococci had numerous latex spheres associated with their surfaces (Fig. $9 \mathrm{~A}$ ) whereas, in the samples treated with the irrelevant isotype control antibody and secondary reagent, the lymphocytes attached to cryptococci did not have latex spheres associated with them (Fig. $9 \mathrm{~B}$ ). These results demonstrate that the immunolabeling was specific for $\mathrm{T}$ lymphocytes and that the effector cells attached to cryptococci were indeed $\mathrm{CD} 3+$, a characteristic of $\mathrm{T}$ cells.

\section{Discussion}

The anticryptococcal activities of human PBMC have been studied by several laboratories, however, there remains some question as to whether lymphocyte subsets are capable of attaching to and inhibiting the growth of cryptococci $(26,33-$ 39 ). Freshly isolated PBMC populations contain four major subsets of cells, B lymphocytes, monocytes, T lymphocytes, and NK cells. The latter three populations of cells have been 

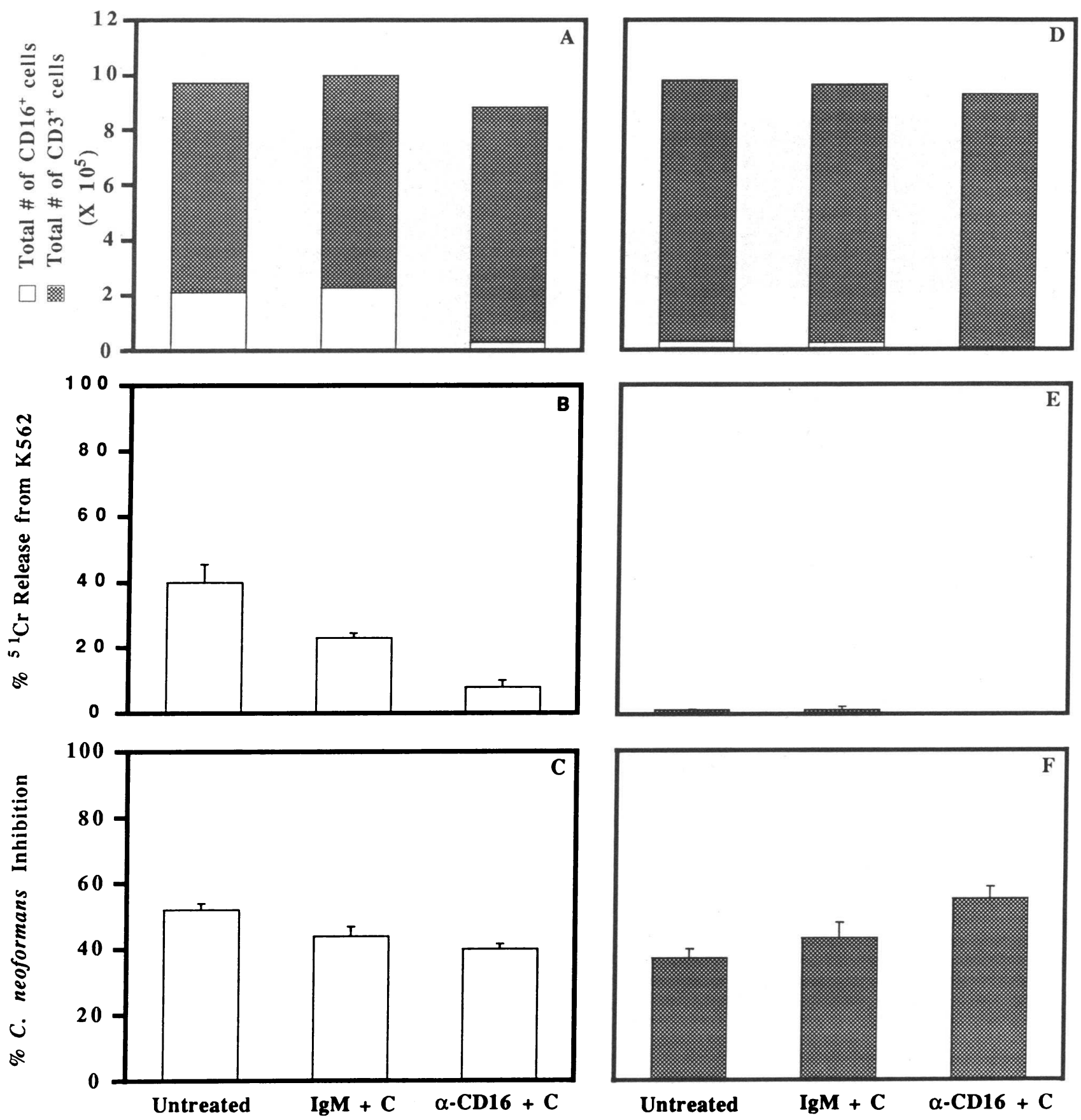

Figure 6. Total numbers of viable CD16+ and CD3+ cells in LGL- and T cell-enriched fractions of NWN PBMC, percent NK cell activity as measured by ${ }^{51} \mathrm{Cr}$ released from $\mathrm{K} 562$ targets, and percent anticryptococcal activity of the LGL and T cell populations before and after treatment of the effector cells with anti-CD16 or control IgM and complement $(C)$. The mean cryptococcal CFU in wells containing only $C$. neoformans cells was $4.75 \times 10^{6} / \mathrm{ml}$. Bars represent the mean \pm the standard error of the mean of quadruplicate samples.

implicated in direct inhibition of $C$. neoformans growth (26, 33-39). There is no question that human monocytes have anticryptococcal activity $(40,41)$, and in the presence, but not in the absence, of anticryptococcal antibody, human NK cells have been shown to inhibit the growth of $C$. neoformans (26). Human mononuclear cells incubated with IL-2 or heat-killed cryptococci for $7 \mathrm{~d}$ are activated to kill $C$. neoformans $(34,35)$. Miller and Puck (42) have shown that human lymphocytes proliferate in response to heat-killed cryptococcal cells and that C. neoformans-specific T cells produce IL-2 when cultured with heat-killed cryptococcal cells; it seems reasonable to speculate that the cells activated to kill cryptococci by culturing in vitro for $7 \mathrm{~d}(34,35)$ are lymphocytes, possibly NK cells or $\mathrm{T}$ lymphocytes.

Our goal was to assess the anticryptococcal activity of NK cells and $\mathrm{T}$ lymphocytes freshly isolated from human peripheral blood. The first step toward achieving this goal was to acquire highly purified fractions of the cell populations of interest, however, it is difficult to obtain populations of NK cells free of contaminating $T$ cells without using procedures that 

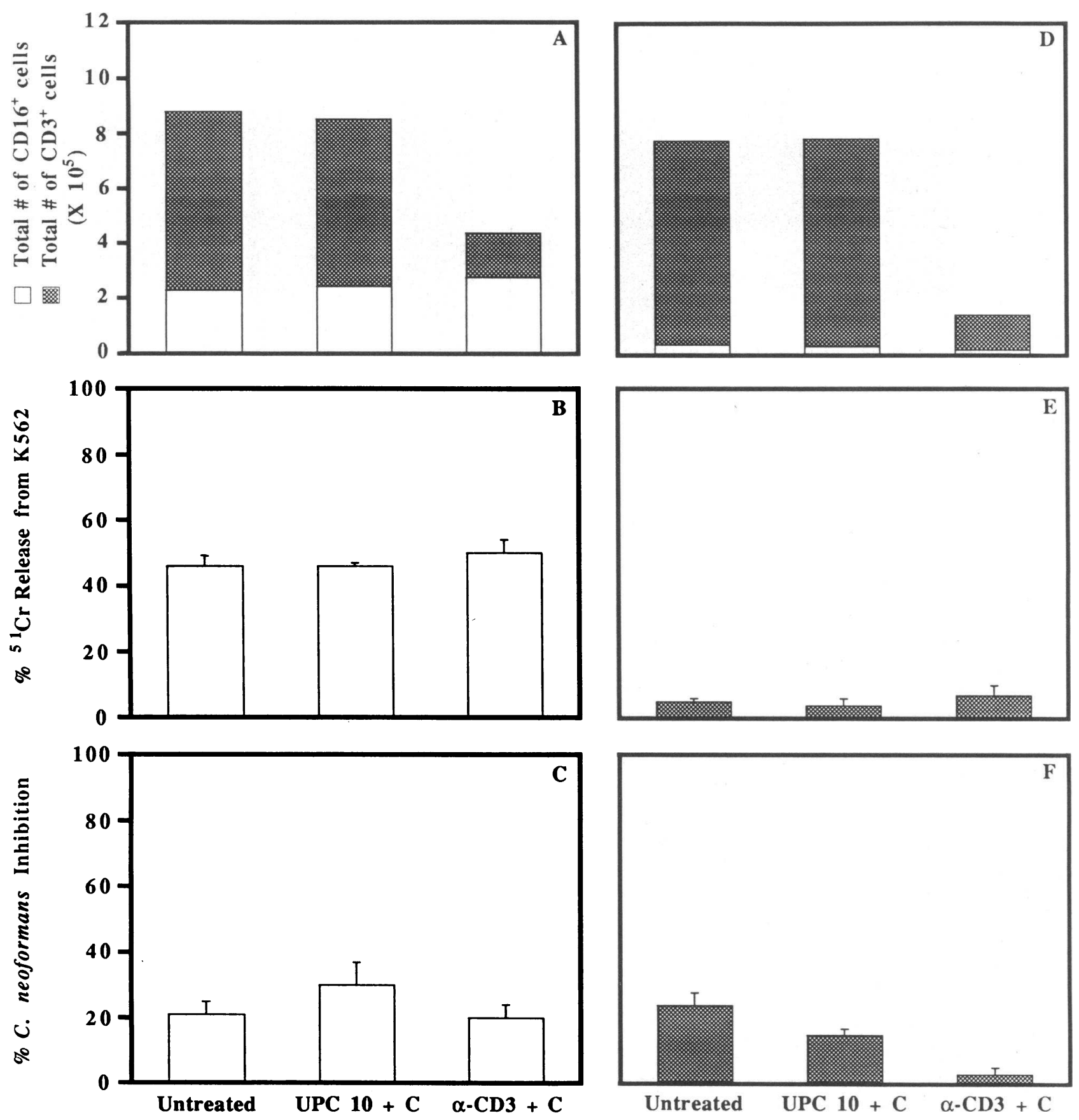

Figure 7. Total numbers of viable CD16+ and CD3+ cells in LGL- and T cell-enriched fractions of NWN PBMC, percent NK cell activity as measured by ${ }^{51} \mathrm{Cr}$ released from K562 targets, and percent anticryptococcal activity of the LGL and T cell populations before and after treatment of the effector cells with anti-CD3 or control UPC 10 and complement $(C)$. The mean cryptococcal CFU in wells containing only $C$. neoformans cells was $4.4 \times 10^{6} / \mathrm{ml}$. Bars represent the mean \pm the standard error of the mean of quadruplicate samples.

might activate the cells. To circumvent this problem, a combination of techniques was used to enrich for the effector cell subsets, including negative selection procedures with antibodies specific for subsets of cells and careful definition of the effector cell populations on the basis of morphology, surface phenotype, level of anti-K562 activity, and type of physical interactions with $C$. neoformans blastoconidia. In addition, we analyzed the anticryptococcal activity of the effector cell populations before and after applying enrichment procedures. By relating the retention or loss of anticryptococcal activity to the morphology, phenotype, and NK cell activity of the cells remaining in the effector cell population after enrichment, we drew conclusions as to the subset( $s$ ) of effector cells responsible for the anticryptococcal activity.

Nylon wool and Percoll fractionation of the PBMC were the initial procedures used to obtain populations of cells enriched for NK and T cells. These methodologies avoid the possibility of activating the effector cell populations. As expected on the basis of investigations by others (30), the LGL fractions, obtained after centrifuging NWN PBMC on discon- 

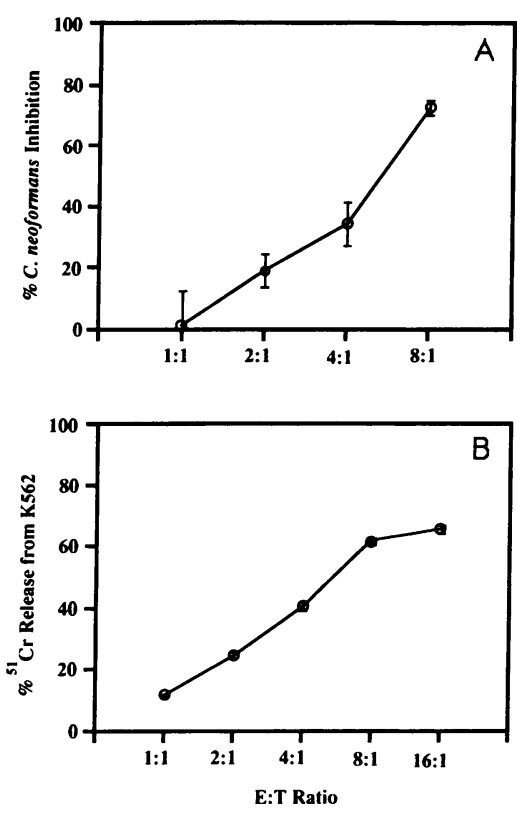

Figure 8. Percent $C$. neoformans growth inhibition and percent NK cell activity as measured by ${ }^{51} \mathrm{Cr}$ released from K562 targets at various $\mathrm{E} / \mathrm{T}$ ratios with the NK cell line, NK 3.3, as effector cells. The mean cryptococcal CFU in wells containing only C. neoformans cells was $3.3 \times 10^{6} / \mathrm{ml}$

tinuous Percoll gradients, contained $<1 \%$ monocytes (CD15+ cells) but were heavily contaminated with $\mathrm{T}(\mathrm{CD} 3+)$ cells. In contrast to the LGL fraction, the T lymphocyte-enriched fractions contained $>92 \% \mathrm{CD} 3+$ cells with $<1 \%$ monocyte and $<5 \%$ NK cell contamination. All of the cell fractions that were enriched for NK and T cells displayed anticryptococcal activity in the absence of $\mathrm{C}$ or anticryptococcal antibody. These data suggested that one or both of these lymphocyte subsets were the active cell fraction. NK cells were implicated as being the effector cells in the NWN fractions on the basis of the fact that NWN fractions of PBMC obtained from 10 different donors displayed anticryptococcal activity that correlated with the NK cell activities to some degree $(r=0.68)$. As we enriched for NK cells in the LGL fractions, the correlation coefficient between NK cell activity and anticryptococcal activity increased to 0.9 . This finding was additional indirect evidence that NK cells were responsible for the inhibition of $C$. neoformans growth. In contrast, when we enriched for $\mathrm{T}$ lymphocytes, even though the $T$ cell-enriched fractions displayed anticryptococcal activity, the correlation with anti-K562 activity diminished to 0.48 . These data support the concept that NK cells are inhibitors of $C$. neoformans growth, but the data also suggest that $\mathrm{T}$ lymphocytes may be directly active against $C$. neoformans. Furthermore, findings that $21-27 \%$ of the cells in the T cell-enriched fraction formed conjugates with $C$. neoformans indicate that human $T$ cells do directly interact with cryptococci. Since the T cell-enriched fractions were contaminated with $<5 \%$ NK cells, it is not reasonable to assume that the NK cells contaminating the $\mathrm{T}$ cell fraction were the cells bound to the cryptococci.

Although it seemed unlikely that the monocytes that copurified with the NK cells or the T cells could be responsible for the anticryptococcal activity observed with the lymphocyte fractions, we assessed the interactions of highly purified monocyte populations with $C$. neoformans and compared the results with the interactions of $C$. neoformans with cells in the LGL or T cell fractions. The anticryptococcal activity displayed by the enriched monocyte populations was mediated by cells having a monocyte phenotype (CD15+, CD16-), as demonstrated by the reduction in anticryptococcal activity after treatment of the monocytes with anti-CD 15 (mouse IgM) and C and by lack of reduction in anticryptococcal activity after treatment with anti-CD16 (mouse IgM) and C. Similar mass cytolysis techniques applied to the LGL and T cell-enriched fractions to remove CD15+ cells did not alter the anticryptococcal activities of the LGL and T cell fractions. Thus, we concluded that the cells having a monocyte phenotype were not responsible for the anticryptococcal activity of the LGL or T cell fractions of human PBMC. This conclusion is supported by two additional observations. First, the monocyte interactions with cryptococci as shown by electron microscopy were different than the interactions of the plastic nonadherent populations with $C$. neoformans, in that the monocytes bound and phagocytized the organism (Fig. 1, $A$ and $B$ ), whereas the cells in the lymphocyte fractions bound to the cryptococci without phagocytizing the organism (Fig. 1, $C-F$ ). Secondly, we observed, as have others (40), that the monocyte-mediated anticryptococcal activity diminished as the $\mathrm{E} / \mathrm{T}$ ratios were reduced from 100:1 to 1:1. In fact, with monocytes as effector cells at a 2:1 E/T ratio, which was the $E / T$ ratio used in the anticryptococcal assays with LGL or $\mathrm{T}$ lymphocytes as effector cells, no anticryptococcal activity was detected (Table II). Considered together, our data eliminate the possibility that contaminating monocytes were responsible for the anticryptococcal activity detected with the LGL and $T$ cell-enriched fractions.

In the experiments in which anti-CD15 and C were used to eliminate monocytes or anti-CD16 and C were used to eliminate NK cells from the LGL or the T cell-enriched fractions, we noted that the anti-CD16 and $C$ treatment did indeed significantly reduce the NK cell activity as measured by ${ }^{51} \mathrm{Cr}$ release from tumor target cells and the anticryptococcal activity of the LGL fraction, however, the treatment did not alter the anticryptococcal activity of the $\mathrm{T}$ cell fraction. These data, like our initial data from studies with NWN cell fractions, indicated that both NK and T lymphocytes were active against cryptococci.

Because we had not phenotyped the effector cells after mass cytolysis in our initial experiments with LGL and T cell fractions (Fig. 5), we repeated the studies with effector cells from three to four additional subjects. With these cell populations, the number of cells having a CD16+ or a CD3+ phenotype, the anti-K562 activity, and the anticryptococcal activity were determined for both the untreated cell populations and the antibody and C-treated effector cell populations. Again, anticryptococcal activity was noted with both the LGL-enriched fraction and T cell-enriched fraction (Figs. 6 and 7). Although the anti-CD16 and $C$ treatment greatly reduced the number of CD16+ cells in the LGL fraction and reduced the NK cell activity as determined by anti-K 562 activity, there was only a minimal reduction in the anticryptococcal activity with the LGL fractions. This latter finding could be explained by the $T$ cells remaining in the anti-CD16 and C-treated samples being responsible for the anticryptococcal activity. These data were corroborated by the data obtained from the $\mathrm{T}$ cell-enriched fractions showing anti-CD3 and $\mathrm{C}$ treatment simultaneously reduced the number of $\mathrm{T}$ lymphocytes $(\mathrm{CD} 3+$ cells $)$ and the anticryptococcal activity. Together, our findings confirm that human $\mathrm{T}$ lymphocytes were involved in inhibition of growth of C. neoformans. It appears that the human T cells act directly on the cryptococci by first binding to the cryptococci because we were able to demonstrate with light and electron microscopy 

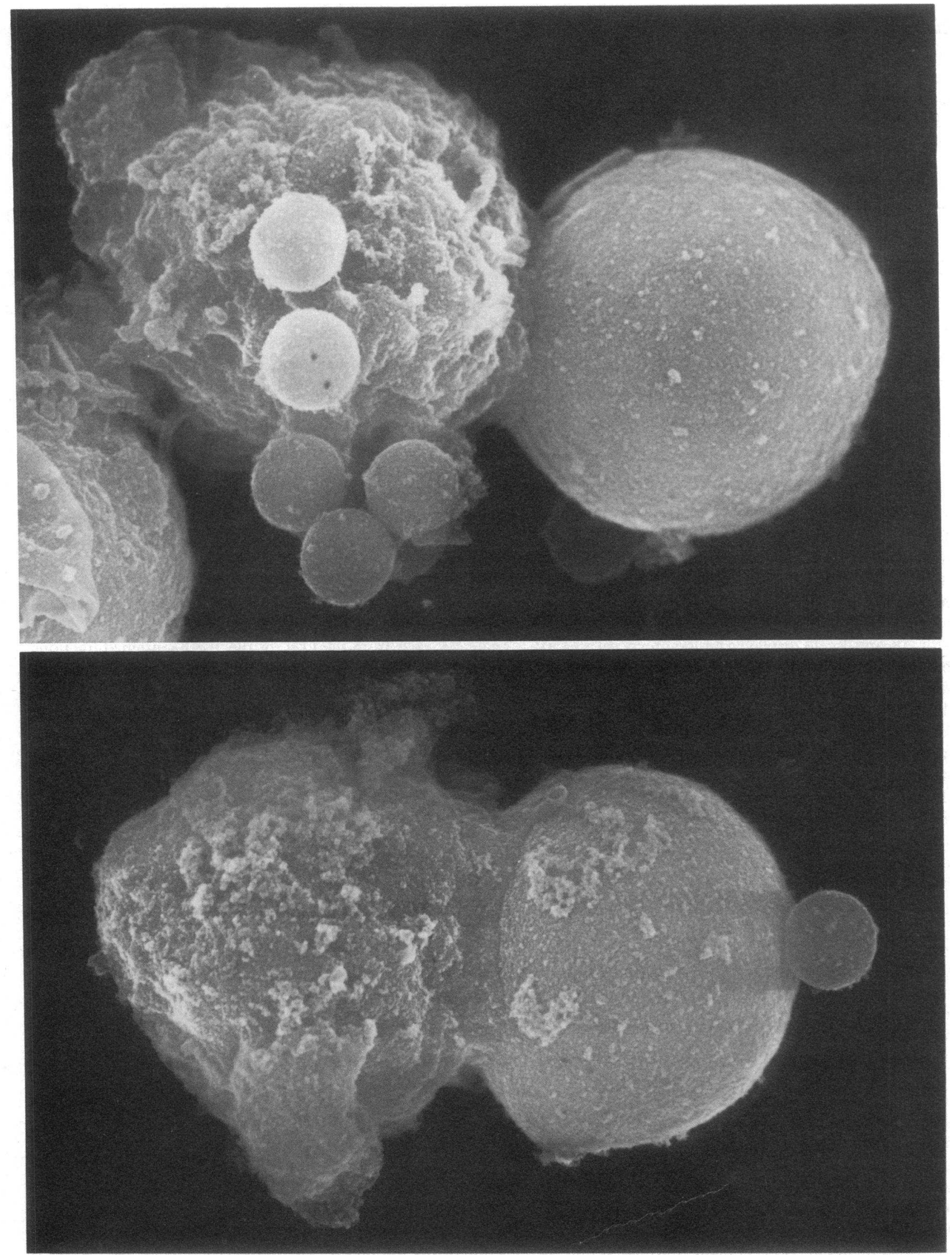

Figure 9. Scanning electron micrographs of conjugates formed between $\mathrm{T}$ cells (left) and $C$. neoformans cells (right). Magnification in both panels is $\times 16,370$. Cells in the top panel were labeled with mouse monoclonal anti-CD3 antibody followed by goat anti-mouse IgG bound to latex beads. Latex beads are seen attached the effector cell (top). Cells in the bottom panel were labeled with UPC10 as a control IgG Iallowed $^{\mathrm{a}}$ by goat anti-mouse IgG conjugated to latex beads. One latex bead is seen associated with the cryptococcal cell; however, no beads attached to the effector cell (bottom). 
(Fig. 1) that cells in the T cell-enriched fractions could form conjugates with the cryptococcal cells. Lymphocytes of the T cell-enriched fraction that attached to cryptococci were shown by immunoelectron microscopy to be CD3+ cells by virtue of their labeling with anti-CD3 (mouse $\mathrm{IgG}_{2 \mathrm{a}}$ ) and rabbit antimouse IgG conjugated to latex beads and not labeling when UPC10 (irrelevant mouse $\operatorname{IgG}_{2 \mathrm{a}}$ ) was substituted for anti-CD3 antibody (Fig. 9).

Our data, from studies in which we showed a strong correlation between anti-K562 activity and anticryptococcal activity with the LGL fraction of effector cells and from our depletion studies with anti-CD16 and C, strongly suggest that human NK cells can limit the growth of cryptococci in the absence of complement or anticryptococcal antibodies. This concept is also supported by the observation that the anti-CD3 and $\mathrm{C}$ treatment of the LGL fraction greatly reduced the numbers of $T$ cells without significantly affecting the NK cell or the anticryptococcal activities. Our conclusion that human NK cells can inhibit the growth of $C$. neoformans differs from the conclusion of Miller et al. (26) who observed that human NK cells killed cryptococci only in the presence of anticryptococcal antibody. We found as did Miller et al. (26) that performing the anticryptococcal assays with an E:T ratio of 100:1 with human LGL as the effector cells did not consistently result in inhibition of cryptococcal growth. However, by using an E/T ratio of 2:1 as we have routinely done for effector cell- $C$. neoformans conjugate assays with murine NK cells (17), we were able to detect anticryptococcal activity of human LGL as well as of human T cells.

With the human NK cell clone NK 3.3 as effector cells, we confirmed that human NK cells can inhibit cryptococcal growth in the absence of opsonizing agents. The NK 3.3 cell line inhibited the growth of $C$. neoformans under the same conditions as were used for the freshly isolated human NK cells. The percent inhibition of $C$. neoformans growth increased as the E/T ratio of NK 3.3 cells to cryptococci was increased from 1:1 to $8: 1$, and the increase in anticryptococcal activity paralleled the increase in NK cell activity observed with increasing $\mathrm{E} / \mathrm{T}$ ratios and $\mathrm{K} 562$ tumor cells as targets. Since NK 3.3 cells are equivalent to IL-2-activated NK cells (28), it may be that the anticryptococcal activity detected with freshly isolated human LGL was mediated by a population of activated NK cells present in the peripheral blood. Further studies are necessary to address this.

Scanning and transmission electron microscopy of the conjugates formed with the LGL-enriched and the T cell-enriched fractions revealed two different types of binding interactions. Many of the LGL effector cells attached to the cryptococci through numerous microvilli whereas almost all of the T lymphocyte effector cells attached to the cryptococcal cells by a large area of membrane adhering like a suction cup to the surface of the cryptococcal cell. Furthermore, all the effector cells bound to cryptococci that labeled with the anti-CD3 and antibody conjugated to latex beads had the physical attachment characteristics described for the $T$ cell fraction. These observations suggest that human NK and $\mathrm{T}$ cells interact differently with cryptococcal targets.

The data presented here show that under in vitro conditions human NK cells as well as T lymphocytes attach to cryptococcal cells and display anticryptococcal activity. Considering the importance of $\mathrm{T}$ lymphocytes in protection against disseminated cryptococcosis (43), it seems reasonable to speculate that $\mathrm{T}$ cells may also interact directly with cryptococci in vivo. Such direct lymphocyte-C. neoformans interactions may be essential in limiting cryptococcal infections either by direct inhibition of cryptococcal growth or by stimulating $\mathrm{T}$ lymphocytes to produce lymphokines that enhance the anticryptococcal activity of other effector cells. With the murine cryptococcosis model, Hill (4) has recently shown that CD4+ T lymphocytes may contribute to the heterogeneity of host cells that surround the cryptococci in the lungs of normal mice. Furthermore, Hill (4) has established that CD4+ T lymphocytes are required for the formation of multinucleated giant cells surrounding encapsulated cryptococci in the lungs and for the sequestering of the cryptococci within the lung alveoli. It is tempting to speculate that human $T$ cells may interact directly with cryptococcal cells in vivo to mediate similar events as those observed in the murine studies. Since humans generally would inhale much smaller doses of cryptococci than those introduced into the lungs of the mice $\left(10^{6} \mathrm{C}\right.$. neoformans $)(4)$, it is expected that, in humans with normal $\mathrm{T}$ cell function, $\mathrm{T}$ cell-mediated mechanisms would eliminate the organism at the site of entry. In contrast, in individuals such as AIDS patients who have greatly reduced $T$ cell numbers, the organism would not be effectively inhibited in the lungs and dissemination would be likely to occur. If the lymphocytes are active against cryptococci in vivo, one would not expect their activity to be limited to the lungs but rather function in any tissue in which the lymphocytes can migrate.

It is unclear from our data whether the $T$ lymphocytes that interact with cryptococci are a population of sensitized $T$ cells that have developed because of previous exposure to $C$. neoformans or a population of $\mathrm{T}$ cells that nonspecifically bind to cryptococci. Since there is little epidemiological data on the percentage of the human population sensitized to cryptococcal antigens, it is impossible at this time to determine if the percentage of individuals with $\mathrm{T}$ cells that display anticryptococcal activity correlates with percentage of individuals with cell-mediated immune reactivity to cryptococcal antigen. We have found that the percentages of human $T$ cells that bind to cryptococci range from 11 to $35 \%$ depending on the individual donor. Thus, it seems that the binding may result from interactions of receptors, other than the specific $T$ cell receptor, that might be found on certain subpopulations of $T$ cells.

\section{Acknowledgments}

Electron microscopy was performed at the Samuel Roberts Noble Electron Microscope Laboratory, Norman, OK. The assistance of Bill Chissoe, Diane Hurd, and Phillip Dang in preparation of the electron micrographs is greatly appreciated.

This study was supported by U. S. Public Health Service grant AI18895 .

\section{References}

1. Armstrong, D. 1988. Life-threatening opportunistic fungal infection in patients with the acquired immunodeficiency syndrome. Ann. NY Acad. Sci. 544:443-450.

2. Kovacs, J. A., A. A. Kovacs, M. Polis, W. C. Wright, V. J. Gill, C. U. Tuazon, E. P. Gelmann, H. C. Lane, R. Longfield, and G. Overturf, et al. 1985. Cryptococcosis in the acquired immunodeficiency syndrome. Ann. Intern. Med. 103:533-538.

3. Laroche, R., B. Dupont, J. E. Touze, H. Taelman, J. Bogaerts, A. Kadio, P. M'Pele, A. Latif, P. Aubry, J. P. Durbec, and J. F. Suniere. 1992. Cryptococcal meningitis associated with acquired immuno-deficiency syndrome (AIDS) in African patients: treatment with fluconazole. J. Med. Vet. Mycol. 30:71-78. 
4. Hill, J. O. 1992. CD4+ T cells cause multinucleated giant cells to form around Cryptococcus neoformans and confine the yeast within the primary site of infection in the respiratory tract. J. Exp. Med. 175:1685-1695.

5. Lim, T. S., J. W. Murphy, and L. K. Cauley. 1980. Host-etiological agent interactions in intranasally and intraperitoneally induced cryptococcosis in mice. Infect. Immun. 29:633-641.

6. Hill, J. O., and A. G. Harmsen. 1991. Intrapulmonary growth and dissemination of an avirulent strain of Cryptococcus neoformans in mice depleted of CD4+ or CD8+ T-cells. J. Exp. Med. 173:755-758.

7. Mody, C. H., M. F. Lipscomb, N. E. Street, and G. B. Toews. 1990. Depletion of CD4+ (L3T4+) lymphocytes in vivo impairs murine host defense to Cryptococcus neoformans. J. Immunol. 144:1472-1477.

8. Huffnagle, G. B., J. L. Yates, and M. F. Lipscomb. 1991. Immunity to a pulmonary Cryptococcus neoformans infection requires both CD4+ and CD8+ T cells. J. Exp. Med. 173:793-800.

9. Hidore, M. R., and J. W. Murphy. 1986. Correlation of natural killer cell activity and clearance of Cryptococcus neoformans from mice after adoptive transfer of splenic nylon wool-nonadherent cells. Infect. Immun. 51:547-555.

10. Hidore, M. R., and J. W. Murphy. 1989. Murine natural killer cell interactions with a fungal target, Cryptococcus neoformans. Infect. Immun. 57:19901997.

11. Hidore, M. R., T. W. Mislan, and J. W. Murphy. 1991. Responses of murine natural killer cells to binding of the fungal target Cryptococcus neoformans. Infect. Immun. 59:1489-1499.

12. Lipscomb, M. F., T. Alvarellos, G. B. Toews, R. Tompkins, Z. Evans, G. Koo, and V. Kumar. 1987. Role of natural killer cells in resistance to Cryptococcus neoformans infections in mice. Am. J. Pathol. 128:354-361.

13. Murphy, J. W., and D. O. McDaniel. 1982. In vitro reactivity of natural killer (NK) cells against Cryptococcus neoformans. J. Immunol. 128:1577-1583.

14. Nabavi, N., and J. W. Murphy. 1985. In vitro binding of natural killer cells to Cryptococcus neoformans targets. Infect. Immun. 50:50-57.

15. Hidore, M. R., N. Nabavi, F. Sonleitner, and J. W. Murphy. 1991. Murine natural killer cells are fungicidal to Cryptococcus neoformans. Infect. Immun. 5:1747-1754.

16. Salkowski, C. A., and E. Balish. 1991. Role of natural killer cells in resistance to systemic cryptococcosis. J. Leukocyte Biol. 50:151-159.

17. Murphy, J. W., M. R. Hidore, and N. Nabavi. 1991. Binding interactions of murine natural killer cells with the fungal target Cryptococcus neoformans. Infect. Immun. 59:1476-1488.

18. Hidore, M. R., N. Nabavi, C. W. Reynolds, P. A. Henkart, and J. W. Murphy. 1990. Cytoplasmic components of natural killer cells limit the growth of Cryptococcus neoformans. J. Leukocyte Biol. 48:15-26.

19. Cauley, L. K., and J. W. Murphy. 1979. Response of congenitally athymic (nude) and phenotypically normal mice to Cryptococcus neoformans infection. Infect. Immun. 23:644-651.

20. Hidore, M. R., and J. W. Murphy. 1986. Natural cellular resistance of beige mice against Cryptococcus neoformans. J. Immunol. 137:3624-3631.

21. Murphy, J. W. 1989. Natural host resistance mechanisms against systemic mycotic agents. In Functions of the Natural Immune System. C. W. Reynolds and R. H. Wiltrout, editors. Plenum Publishing Corp., New York. 149-184.

22. Deepe, G. S., and W. E. Bullock. 1990. Immunological aspects of fungal pathogenesis. Eur. J. Clin. Microbiol. Infect. Dis. 9:377-380.

23. Murphy, J. W. 1989. Cryptococcosis. In Immunology of the Fungal Diseases. R. A. Cox, editor. CRC Press, Boca Raton, FL. 93-138.

24. Fung, P. Y., and J. W. Murphy. 1982. In vitro interactions of immune lymphocytes and Cryptococcus neoformans. Infect. Immun. 36:1128-1138.
25. Trinchieri, G. 1989. Biology of natural killer cells. Adv. Immunol. 47:187375.

26. Miller, M. F., T. G. Mitchell, W. J. Storkus, and J. R. Dawson. 1990 Human natural killer cells do not inhibit growth of Cryptococcus neoformans in the absence of antibody. Infect. Immun. 58:639-645.

27. Hoffman, R. A., P. C. Kung, W. P. Hansen, and G. Goldstein. 1980 Simple and rapid measurement of human $T$ lymphocytes and their subclasses in peripheral blood. Proc. Natl. Acad. Sci. USA. 77:4914-4917.

28. Kornbluth, J., N. Flomenberg, and B. Dupont. 1982. Cell surface phenotype of a cloned line of human natural killer cells. J. Immunol. 129:2831-2837.

29. Hanjan, S. N. S., J. K. Kearney, and M. D. Cooper. 1982. A monoclonal antibody (MMA) that identifies a differentiation antigen on human myelomonocyte cells. Clin. Immunol. Immunopathol. 23:172.

30. Lanier, L. L., A. M. Le, C. I. Civin, M. R. Loken, and J. H. Phillips. 1986 The relationship of CD16 (Leu-11) and Leu-19 (NKH-1) antigen expression on human peripheral blood NK cells and cytotoxic T lymphocytes. J. Immunol. 136:4480-4486.

31. Stewart, C. C., S. J. Stewart, and R. C. Habbersett. 1989. Resolving leukocytes using axial light loss. Cytometry. 10:426-432.

32. Timonen, T., J. R. Ortaldo, and R. B. Herberman. 1981. Characteristics of human large granular lymphocytes and relationship to natural killer and $\mathrm{K}$ cells. J. Exp. Med. 153:569-582.

33. Diamond, R. D., R. K. Root, and J. E. Bennett. 1972. Factors influencing killing of Cryptococcus neoformans by human leukocytes in vitro. J. Infect. Dis. 125:367-376.

34. Levitz, S. M., T. P. Farrell, and R. T. Maziarz. 1991. Killing of Cryptococcus neoformans by human peripheral blood mononuclear cells stimulated in culture. J. Infect. Dis. 163:1108-1113.

35. Levitz, S. M. 1991. Activation of human peripheral blood mononuclear cells by interleukin-2 and granulocyte-macrophage colony-stimulating factor to inhibit Cryptococcus neoformans. Infect. Immun. 59:3393-3397.

36. Diamond, R. D. 1974. Antibody-dependent killing of Cryptococcus neoformans by human peripheral blood mononuclear cells. Nature (Lond.). 247:148-150.

37. Diamond, R. D., and A. C. Allison. 1976. Nature of the effector cells responsible for antibody-dependent cell-mediated killing of Cryptococcus neoformans. Infect. Immun. 14:716-720.

38. Washburn, R. G., C. U. Tuazon, and J. E. Bennett. 1985. Phagocytic and fungicidal activity of monocytes from patients with acquired immunodeficiency syndrome. J. Infect. Dis. 151:565-566.

39. Bobak, D. A., R. G. Washburn, and M. M. Frank. 1988. Clq enhances the phagocytosis of Cryptococcus neoformans blastospores by human monocytes. $J$. Immunol. 141:592-597.

40. Miller, M. F., and T. G. Mitchell. 1991. Killing of Cryptococcus neoformans strains by human neutrophils and monocytes. Infect. Immun. 59:24-28.

41. Levitz, S. M., and T. P. Farrell. 1990. Growth inhibition of Cryptococcus neoformans by cultured human monocytes: role of the capsule, opsonins, the culture surface, and cytokines. Infect. Immun. 58:1201-1209.

42. Miller, G. P. G., and J. Puck. 1984. In vitro human lymphocyte responses to Cryptococcus neoformans. Evidence for primary and secondary responses in normal and infected subjects. J. Immunol. 133:166-172.

43. Masur, H., F. P. Ognibene, R. Yarchoan, J. H. Shelhamer, B. F. Baird, W. Travis, A. F. Suffredini, L. Deyton, J. A. Kovacs, J. Falloon, et al. 1989. CD4 counts as predictors of opportunistic pneumonias in human immunodeficiency virus (HIV) infection. Ann. Intern. Med. 111:223-231. 